\title{
Prevention of multidrug resistance (MDR) in osteosarcoma by NSC23925
}

\author{
X Yang ${ }^{1,2}$, P Yang ${ }^{1}$, J Shen ${ }^{1}$, E Osaka ${ }^{1}, \mathrm{E} \mathrm{Choy}^{1}$, G Cote ${ }^{1}$, D Harmon ${ }^{1}$, Z Zhang ${ }^{2}$, H Mankin ${ }^{1}$, F J Hornicek ${ }^{1}$ \\ and Z Duan*,1 \\ ${ }^{1}$ Sarcoma Biology Laboratory, Center for Sarcoma and Connective Tissue Oncology, Massachusetts General Hospital and Harvard \\ Medical School, 100 Blossom Street, Jackson 1115, Boston, MA 02114, USA and ${ }^{2}$ Department of Gynaecology and Obstetrics, The \\ Third Affiliated Hospital of Zhengzhou University, Zhengzhou 450052, Henan Province, China
}

\begin{abstract}
Background: The major limitation to the success of chemotherapy in osteosarcoma is the development of multidrug resistance (MDR). Preventing the emergence of MDR during chemotherapy treatment has been a high priority of clinical and investigational oncology, but it remains an elusive goal. The NSC23925 has recently been identified as a novel and potent MDR reversal agent. However, whether NSC23925 can prevent the development of MDR in cancer is unknown. Therefore, this study aims to evaluate the effects of NSC23925 on prevention of the development of MDR in osteosarcoma.
\end{abstract}

Methods: Human osteosarcoma cell lines U-2OS and Saos were exposed to increasing concentrations of paclitaxel alone or in combination with NSC23925 for 6 months. Cell sublines selected at different time points were evaluated for their drug sensitivity, drug transporter P-glycoprotein (Pgp) expression and activity.

Results: We observed that tumour cells selected with increasing concentrations of paclitaxel alone developed MDR with resistance to paclitaxel and other Pgp substrates, whereas cells cultured with paclitaxel-NSC23925 did not develop MDR and cells remained sensitive to chemotherapeutic agents. Paclitaxel-resistant cells showed high expression and activity of the Pgp, whereas paclitaxel-NSC23925-treated cells did not express Pgp. No changes in IC $\mathrm{C}_{50}$ and Pgp expression and activity were observed in cells grown with the NSC23925 alone.

Conclusions: Our findings suggest that NSC23925 may prevent the development of MDR by specifically preventing the overexpression of Pgp. Given the significant incidence of MDR in osteosarcoma and the lack of effective agents for prevention of MDR, NSC23925 and derivatives hold the potential to improve the outcome of cancer patients with poor prognosis due to drug resistance.

Osteosarcoma is one of the most common and aggressive primary malignant bone tumours in childhood and adolescence. Current standard treatment of osteosarcoma involves surgical resection and combination chemotherapy (Marina et al, 2004; Chou et al, 2008). Although this therapy helps tumour cytoreduction and remission rate, the long-term survival rate remains at $\sim 60-70 \%$ (Marina et al, 2004; Sakamoto and Iwamoto, 2008). Osteosarcoma is still characterised by frequent relapse and metastatic disease that is associated with the development of multidrug resistance (MDR) to chemotherapy in late stages (Chou and Gorlick, 2006; Dieudonne et al, 2010). Tumour cells that are initially sensitive to chemotherapeutic drugs often develop resistance to those drugs as well as to other functionally and structurally unrelated anticancer agents later, thus limiting the overall utility of chemotherapeutic drugs (Agarwal and Kaye, 2003; Chou and Gorlick, 2006). The development of MDR is a major obstacle to cancer chemotherapy and is a significant challenge to successful cancer treatment (Gillet and Gottesman, 2010). Several mechanisms have been shown to potentiate osteosarcoma to become resistant to chemotherapeutic agents (Chou and Gorlick, 2006). One of the best characterised MDR mechanisms is overexpression of ATP-binding cassette $(\mathrm{ABC})$ drug transporters P-glycoprotein protein (Pgp) that causes

*Correspondence: Professor Z Duan; E-mail: zduan@mgh.harvard.edu

Received 19 February 2014; revised 10 April 2014; accepted 14 April 2014; published online 22 May 2014

(c) 2014 Cancer Research UK. All rights reserved 0007-0920/14 
decreased drug uptake and increased drug efflux in MDR cells (Gottesman et al, 2002; Ozben, 2006; Higgins, 2007). P-glycoprotein protein is the protein product of multidrug resistance gene 1 (MDR1), and acts as an energy-dependent drug efflux pump requiring two ATPs as the energy source to pump out many structurally unrelated chemotherapeutic drugs (Gottesman et al, 2002). Overexpression of Pgp has been found in multiple MDR osteosarcoma cell lines and osteosarcoma drug resistance tissues (Bodey et al, 1995; Suto et al, 1998; Chano et al, 2004; Okada et al, 2006; Susa et al, 2010). Strategies of reversing and preventing MDR by targeting Pgp have been studied extensively in different MDR model systems including osteosarcoma but with limited success (Decaudin et al, 2002; Ryu et al, 2010; Kobayashi et al, 2012).

Most of the previous investigations have been focussed on the reversal rather than prevention of Pgp-mediated MDR. Four generations of Pgp inhibitors have been developed (Shukla et al, 2011), including verapamil, PSC833 (valspodar), VX-710 (biricodar), XR9576 (tariquidar), R101933 (laniquidar) and a natural product, curcumin (Lin et al, 2007; Gupta et al, 2012). However, preventing the development of MDR during the course of chemotherapy and exploring the underlying molecular machinery rather than reversing MDR once it has arisen may fundamentally aid in the design of strategies for overcoming MDR in cancer. In recent years, several studies have investigated the prevention of initiation of MDR in cancer after chemotherapy drug treatment (Batrakova et al, 2006; Tooker et al, 2007; Sharma et al, 2008). A number of drugs, such as verapamil, cyclosporin A (CsA), VX710, XR9576, P85 (Pluronic 85) and LGD1069 (bexarotene) have been tested as the preventers that avert the development of MDR (Cocker et al, 2001; Yen et al, 2004; Yen and Lamph, 2006). Several clinical trials have been performed using these preventers in different types of cancer patients (Baer et al, 2002; Minderman et al, 2004; Kelly et al, 2011). However, significant effects on prevention of MDR for most of these preventers have not been established, and notable survival benefits have not been shown in clinical trials (Gandhi et al, 2007; Lhomme et al, 2008; Kolitz et al, 2010; O'Brien et al, 2010). Therefore, development of more potent and selective MDR preventers is needed.

The NSC23925 (2-(4-methoxyphenyl)-4-quinolinyl) (2-piperidinyl) methanol) is a small molecular compound that was identified as an effective and selective inhibitor of Pgp in previous studies. It was demonstrated that NSC23925 has the ability to reverse Pgp-mediated MDR in ovarian cancer by stimulating Pgp ATPase activity in vitro. The NSC23925 was 20 -fold more potent than verapamil and 50-fold more potent than CsA at the same concentrations to reverse drug resistance (Duan et al, 2009a). Importantly, the combination of paclitaxel and NSC23925 produced a significant inhibitory effect on the growth of xenograft ovarian cancer MDR tumour models as compared with animals treated with paclitaxel alone (Duan et al, 2012). However, whether NSC23925 is able to prevent the development of MDR in cancer is unknown. Therefore, in this study, we evaluated the effects of NSC23925 on the prevention of the development of MDR in the osteosarcoma cell lines U-2OS and Saos.

\section{MATERIALS AND METHODS}

Cell lines, drugs and antibodies. Human osteosarcoma cell lines U-2OS and Saos were purchased from American Type Culture Collection (ATCC, Manassas, VA, USA). Both of the cell lines were routinely cultured in RPMI-1640 (Life Technologies, Grand Island, NY, USA) supplemented with $10 \%$ fetal bovine serum (FBS) and $1 \%$ penicillin/streptomycin (Life Technologies) in $5 \% \mathrm{CO}_{2}-95 \%$ air atmosphere at $37^{\circ} \mathrm{C}$.
Prior analyses have demonstrated that there are two chiral centres in the structure of NSC23925 that lead to four different isomers. Isomer 11 of NSC23925 is the most potent one for the reversal of MDR (Duan et al, 2012). Therefore, isomer 11 was used in this study. Isomer 11 of NSC23925 (abbreviated as NSC23925) was synthesised by ChemPartner Co. (Chengdu, China) and has been validated to reverse MDR (Duan et al, 2012). Paclitaxel, docetaxel, doxorubicin, vincristine, gemcitabine, cisplatin and methotrexate were obtained from the pharmacy at the Massachusetts General Hospital. PM-00104 was supplied by PharmaMar (Madrid, Spain). The mouse monoclonal antibodies to human Pgp and MRP1 were purchased from Sigma-Aldrich (St Louis, MO, USA). The mouse monoclonal antibody to human BCRP was acquired from EMD Millipore (Bedford, MA, USA).

Development of resistant osteosarcoma cell lines. To evaluate the effect of NSC23925 on preventing the development of paclitaxel resistance, $1 \times 10^{5} \mathrm{U}-2 \mathrm{OS}$ and Saos cells were seeded in $75 \mathrm{~cm}^{2}$ tissue culture flasks containing RPMI-1640 with $10 \%$ FBS and 1\% penicillin/streptomycin. Establishment of the resistant osteosarcoma cells lines followed similar previously described protocols (Cocker et al, 2001; Sharma et al, 2008). The culture medium was supplemented with either $0.0001 \mu \mathrm{M}$ paclitaxel alone, the combination of $0.0001 \mu \mathrm{m}$ paclitaxel and $1 \mu \mathrm{M}$ NSC23925 or $1 \mu \mathrm{M}$ NSC23925 alone. When growth of the cells reached $90 \%$ confluence, the cells were harvested and reseeded at the density of $1 \times 10^{5}$ cells/flask, and the concentration of paclitaxel was increased. At different selection points, cell sublines were stored in liquid nitrogen for further studies. The MDR cell line U-2OSR2, which was previously established from U-2OS, was used as a control (Duan et al, 2009b).

Cytotoxicity assay. Cytotoxicity of anticancer drugs in selected cell sublines was assessed by MTT assay as previously described (Duan et al, 2012). Briefly, cytotoxicity of anticancer drugs in selected cell sublines was assessed by MTT assay. Cells were seeded in 96-well plates at the density of $3.5 \times 10^{3}$ cells per well and exposed to different concentrations of anticancer drugs for 5 days. Subsequently, $20 \mu$ l MTT (Sigma-Aldrich) was added to each well. After incubation for $4 \mathrm{~h}$, the resulting formazan products were dissolved with acid-isopropanol. The absorbance at a wavelength of $490 \mathrm{~nm}$ was measured on a SpectraMax Microplate Spectrophotometer (Molecular Devices LLC, Sunnyvale, CA, USA). Experiments were performed in triplicate. Absorbance values were normalised assigning the value of the cells in medium without drug to 1.0 and the value of the no-cell control to 0 .

Western blot assay. To evaluate the protein expression of Pgp and other ABC transporters including MRP1 and BCRP in different selected cell sublines, total proteins were extracted with $1 \times$ RIPA lysis buffer (Upstate Biotechnology, Charlottesville, VA, USA). Protein concentrations were evaluated by the DC Protein Assay (Bio-Rad, Hercules, CA, USA), and western blot analysis was then performed as previously described (Duan et al, 2009b). Briefly, $20 \mu \mathrm{g}$ of total protein was resolved on NuPAGE 4-12\% Bis-Tris Gel (Life Technologies) and transferred onto nitrocellulose membrane (Bio-Rad). The membrane was then blocked in Tris-buffered saline with $0.1 \%$ Tween-20 (TBST) containing 5\% nonfat milk for $2 \mathrm{~h}$ and subsequently probed with primary antibodies (dilution: $1: 1000$ ) at $4{ }^{\circ} \mathrm{C}$ overnight. After washing three times with TBST, they were further incubated with respective secondary antibodies (LI-COR Biosciences, Lincoln, NE, USA) in a dilution of $1: 20000$ for $1 \mathrm{~h}$ at room temperature. The membranes were washed again with TBST and rinsed with PBS. Finally, membranes were scanned using Odyssey CLx equipment (LI-COR Biosciences).

Immunofluorescence assay. Different U-2OS cell sublines were grown in 24-well plate for $48 \mathrm{~h}$ and fixed in $3.7 \%$ buffered 
paraformaldehyde. After permeating with methanol for $20 \mathrm{~min}$, the cells were blocked with $1 \%$ BSA in PBS for $1 \mathrm{~h}$. Subsequently, the cells were incubated with Pgp antibody (dilution: $1: 50$ ) at $4{ }^{\circ} \mathrm{C}$ overnight. After washing three times with PBS, the cells were then incubated with Alexa Fluor 594 (Red)-conjugated goat anti-mouse antibody (Invitrogen, Carlsbad, CA, USA) in a dilution of $1: 1000$ for half an hour. The nuclei were stained with $1 \mu \mathrm{g} \mathrm{ml}^{-1}$ Hoechst 33342 (Life Technologies). Images were obtained by Nikon Eclipse Ti-U fluorescence microscope (Nikon Instruments, Inc., Melville, NY, USA) equipped with a SPOT RT digital camera (Diagnostic Instruments, Inc., Sterling Heights, MI, USA).

Drug uptake assay determined by fluorescence microscopy. For visualisation of the intracellular accumulation level of Pgp substrate Calcein AM and Rhodamine 123 (R123) in different U-2OS cell sublines, $2 \times 10^{4}$ cells were seeded in 12 -well plate in duplicate the day before the assay. Cells were then incubated with either $0.25 \mu \mathrm{M}$ Calcein AM or $1 \mu \mathrm{M}$ R123 in RPMI-1640 medium for $2 \mathrm{~h}$ at $37^{\circ} \mathrm{C}$. After washing the cells with PBS, $1 \mu \mathrm{g} \mathrm{ml} l^{-1}$ Hoechst 33342 was used to stain nuclei. Images were acquired by Nikon Eclipse Ti-U fluorescence microscope equipped with a SPOT RT digital camera.

Calcein AM retention assay. At 1 day before the assay, $2 \times 10^{4}$ cells of different U-2OS cell sublines were cultured in a 96-well plate in triplicate. Cells were then incubated with $0.25 \mu \mathrm{m}$ calcein AM for $15 \mathrm{~min}$. After rinsing with cold culture medium, the cell fluorescence was measured at absorption wavelength $494 \mathrm{~nm}$ and emission wavelength $517 \mathrm{~nm}$ on a SPECTRAmax GeminXS fluorescent spectrophotometer (Molecular Devices), and normalised for cellular protein levels as determined by DC Protein Assay. The absorbance values were normalised against the value of the parental U-2OS and Saos cells.

R123 accumulation and efflux assay. Different U-2OS cell sublines were seeded at $4 \times 10^{4} /$ well in two separate 96 -well plates in triplicate 1 day before the assay. Both plates were washed three times with serum-free RPMI-1640 on day 2, and the cells were then incubated with $3.2 \mu \mathrm{M}$ R123 in serum-free RPMI-1640 culture medium for $1 \mathrm{~h}$ at $37^{\circ} \mathrm{C}$. One plate was gently washed three times with ice-cold PBS to remove extracellular R123 and lysed in Triton X-100 (1.0\%). Intracellular R123 content was determined using a SPECTRAmax GeminXS fluorescent spectrophotometer $(\lambda \mathrm{ex}=492 \mathrm{~nm}, \lambda \mathrm{em}=535 \mathrm{~nm})$ and normalised for cellular protein levels as determined by DC Protein Assay. This value was labeled as $\mathrm{R}_{\mathrm{a}}$. The second plate was washed three times with ice-cold serum-free RPMI-1640 culture medium, and incubated with serum-free RPMI 1640 for another $1 \mathrm{~h}$. Subsequently, cells were washed three times with ice-cold PBS and lysed in Triton X-100 (1.0\%). R123 content was determined as described above and the values were labeled as $R_{e}$. The relative $\mathrm{R} 123$ cellular efflux level was calculated by $\left(\mathrm{R}_{\mathrm{a}}-\mathrm{R}_{\mathrm{e}}\right) / \mathrm{R}_{\mathrm{a}}$. The absorbance values were normalised against the value of the parental U-2OS cells.

Statistical analysis. Statistical analysis was done using GraphPad Prism 5 software (GraphPad Software, Inc., La Jolla, CA, USA). Data were presented as the mean \pm s.d. For comparison between two groups, a two-sided Student's $t$-test was used. $P<0.05$ value was considered as statistically significant.

\section{RESULTS}

NSC23925 prevents the emergence of MDR during paclitaxel treatment. To establish MDR cell sublines, osteosarcoma cell lines U-2OS and Saos were cultured either with increasing concentrations of paclitaxel alone or in combination with $1 \mu \mathrm{M}$ NSC23925 (paclitaxel-NSC23925). U-2OS cells selected with paclitaxel alone (U-2OS/paclitaxel) grew steadily in the presence of $0.2 \mu \mathrm{M}$ paclitaxel in culture medium after 6 months of drug exposure. In contrast, cells cultured with paclitaxel-NSC23925 combination (U-2OS/paclitaxel-NSC23925) were unable to grow in the medium with more than $0.006 \mu \mathrm{M}$ paclitaxel (Figure 1A). Similar to U-2OS, Saos cells selected with paclitaxel alone (Saos/paclitaxel) showed stable growth in the presence of $0.06 \mu \mathrm{M}$ paclitaxel after half-year, whereas cells cultured with paclitaxel-NSC23925 combination (Saos/paclitaxel-NSC23925) could not tolerate more than $0.001 \mu \mathrm{M}$
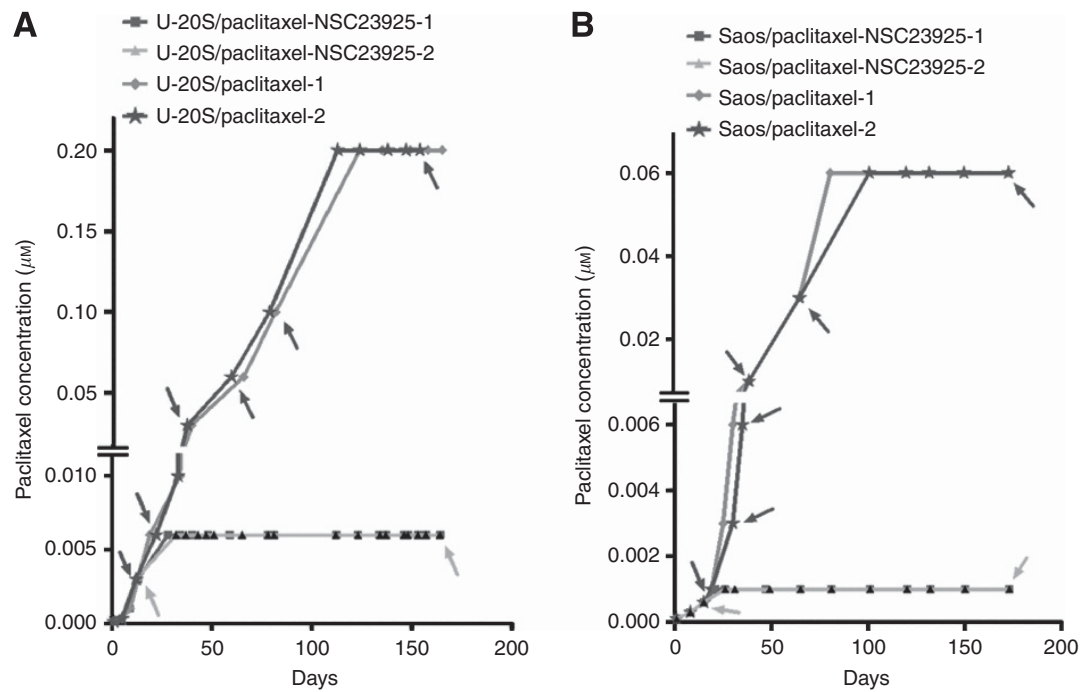

Figure 1. Development of drug resistance in U-2OS and Saos cell lines during paclitaxel treatment. (A) The time course of development of paclitaxel resistance in U-2OS cell line in the absence or in the presence of $1 \mu \mathrm{m}$ NSC23925. (B) The time course of development of paclitaxel resistance in Saos cell line. Two independent experiments were established simultaneously in cells selected with paclitaxel alone, and resistance U-2OS and Saos cell lines developed on both occasions (paclitaxel-1 and paclitaxel-2). The experiments of cells cultured with the paclitaxelNSC23925 combination were also repeated independently two times, in which the use of NSC23925 prevented the development of resistance to paclitaxel on both occasions (paclitaxel-NSC23925-1 and paclitaxel-NSC23925-2). Different selection points for cell sublines indicated by arrows in the time course of paclitaxel-1 and paclitaxel-NSC23925-1 were used in the further experiments. 
paclitaxel in culture medium (Figure 1B). Two independent experiments were established simultaneously in osteosarcoma cells selected with paclitaxel alone, and resistant U-2OS and Saos cell lines were developed in all of these experiments. The experiments of cells cultured with paclitaxel-NSC23925 combination were also repeated independently two times, and NSC23925 was shown to prevent the introduction and development of resistance to paclitaxel in both of these events. Cell sublines used for further experiments were harvested and frozen at different selection points, as shown by arrows in Figure 1A and B. In addition, U-2OS and Saos cells cultured with $1 \mu \mathrm{m}$ NSC23925 (U-2OS/NSC23925, Saos/NSC23925) alone were grown stably for 2 months (data were not shown).

The $\mathrm{IC}_{50}$ of paclitaxel was then evaluated to further determine paclitaxel resistance. As expected, the $\mathrm{IC}_{50}$ of paclitaxel in cell sublines revealed the same trend as their tolerance to paclitaxel during selection (Figure $2 \mathrm{~A}$ and $\mathrm{B}$ ). The $\mathrm{IC}_{50}$ of paclitaxel in cells selected with paclitaxel alone increased as the time and concentration of drug exposure increased. U-2OS cells selected with $\geqslant 0.06 \mu \mathrm{m}$ of paclitaxel alone showed significantly higher $\mathrm{IC}_{50}$ of paclitaxel as compared with the parental cells. An increase of 72.1-fold in $\mathrm{IC}_{50}$ of paclitaxel was observed in U-2OS cells selected with $0.2 \mu \mathrm{M}$ paclitaxel alone (U-2OS/paclitaxel $\mathrm{l}_{0.2}$ ) as compared with parental cells. However, the $\mathrm{IC}_{50}$ of paclitaxel in cells cultured with $0.006 \mu \mathrm{M}$ paclitaxel-NSC23925 combination (U-2OS/paclitaxel $_{0.006}$-NSC23925) increased by 0.8 -fold only, further suggesting that paclitaxel-NSC23925 combination prevented the development of paclitaxel resistance. Specifically, the $\mathrm{IC}_{50}$ of paclitaxel in U-2OS/ paclitaxel $_{0.2}$ cells was 40.1-fold as high as that of U-2OS/ paclitaxel . $_{006}-\mathrm{NSC} 23925$ cells (Figure 2A and Supplementary Table 1). Similar results were shown in Saos cell sublines (Figure 2B and Supplementary Table 2). There was no change in $\mathrm{IC}_{50}$ of paclitaxel in cells cultured with $1 \mu \mathrm{M}$ NSC23925 alone (Figure 2).

Because paclitaxel-NSC23925 prevented the emergence of paclitaxel resistance, we further examined whether this combination could prevent acquired drug resistance to other cytotoxic agents. The $\mathrm{IC}_{50}$ of docetaxel, doxorubicin, vincristine, PM-00104, gemcitabine, cisplatin and methotrexate in U-2OS cell sublines were used to examine the cross-resistance profiles. U-2OS/paclitaxel ${ }_{0.2}$ cells revealed 28.9-fold increased cross-resistance to doxorubicin, whereas U-2OS/paclitaxel ${ }_{0.006}$-NSC23925 cells remained sensitive to doxorubicin. Sensitivity to other well-known Pgp substrate drugs, such as docetaxel, vincristine and PM-00104, was also notably reduced in U-2OS/paclitaxel ${ }_{0.2}$ cells. Nevertheless, U-2OS/paclitaxel ${ }_{0.006}-\mathrm{NSC} 23925$ cells remained sensitive to docetaxel, vincristine and PM-00104 (Figure 3 and Supplementary Table 3). Therefore, cells selected with paclitaxel alone naturally acquired MDR, whereas MDR did not develop in cells cultured with paclitaxel-NSC23925 combination. These results, taken together, indicated that NSC23925 has the ability to prevent the emergence of MDR in cancer cells treated with paclitaxel. In addition, the cytotoxicity of cisplatin and methotrexate that are known to be unaffected by Pgp mechanisms were not altered in $\mathrm{U}-2 \mathrm{OS} /$ paclitaxel $_{0.006}-\mathrm{NSC} 23925$ and U-2OS/paclitaxel $\mathrm{p}_{0.2}$ cells (Figure 3 and Supplementary Table 3).

NSC23925 specifically prevents Pgp overexpression during chemotherapeutic drug treatment. The expression levels of Pgp in different cell sublines were evaluated to further identify the underlying mechanisms of preventing MDR development by NSC23925. Western blot analysis demonstrated that U-2OS/ paclitaxel and Saos/paclitaxel cells selected with $\geqslant 0.06 \mu \mathrm{M}$ paclitaxel alone expressed significantly higher levels of Pgp; however, no significant induction of Pgp expression was observed in U-2OS/paclitaxel-NSC23925 and Saos/paclitaxel-NSC23925 cells as compared with parental cells (Figure 4A and B). The relative Pgp expression level was analysed by densitometry and the results are presented in Figure 4C. The increase in Pgp level detected in the different cell sublines showed a strong association with the increase in the concentration of paclitaxel tolerated by cells. These results suggested that exposure of cells to paclitaxel led to overexpression of Pgp, and that increased Pgp expression level was responsible for the emergence of MDR. NSC23925 can prevent the development of MDR in cancer cells through the inhibition of Pgp expression. These findings were further confirmed by immunofluorescence. The U-2OS/paclitaxel $\mathrm{L}_{0.2}$ cells displayed significantly higher Pgp staining than U-2OS/paclitaxel $\mathrm{l}_{0.006^{-}}$ NSC23925 cells (Figure 4D). Cells selected with $1 \mu \mathrm{M}$ NSC23925 alone did not affect Pgp expression.
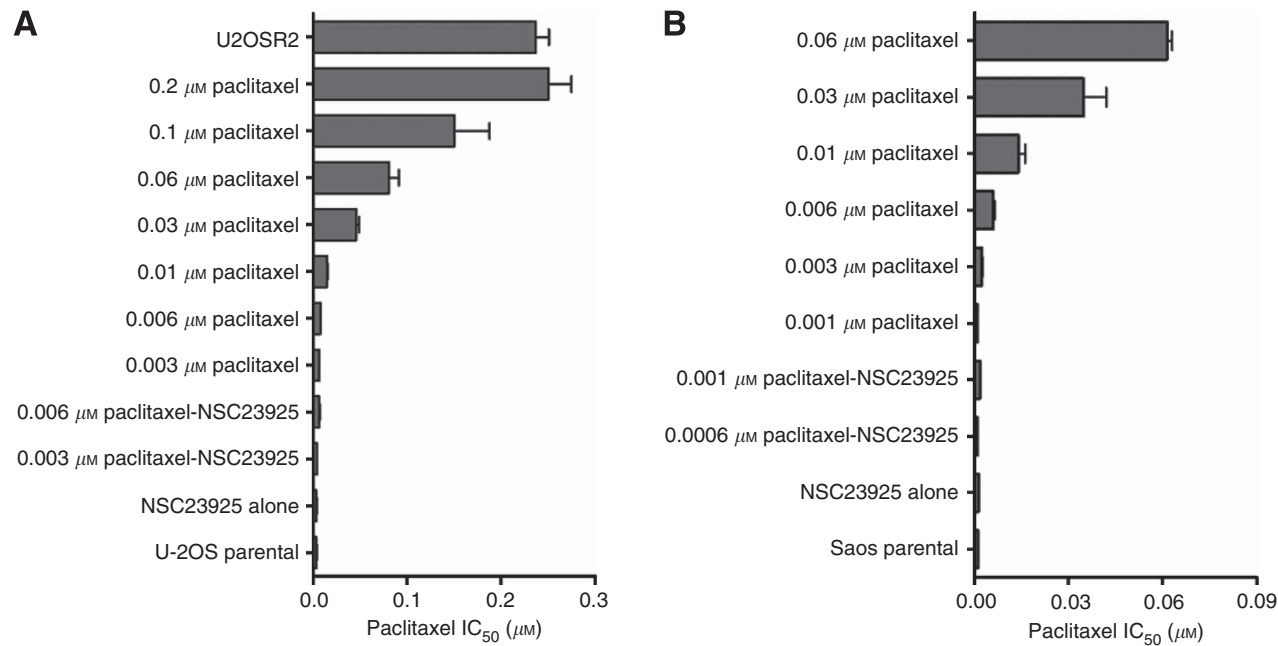

Figure 2. The NSC23925 prevented the emergence of paclitaxel resistance during chemotherapeutic agents. (A) The IC 50 of paclitaxel in U-2OS parental cell and selected cell sublines. The labels correspond to U-2OS parental cells (U-2OS parental); cells cultured with $1 \mu \mathrm{m}$ NSC23925 alone (NSC23925 alone); cells cultured with $0.003 \mu \mathrm{m}$ paclitaxel in the presence of $1 \mu \mathrm{m}$ NSC23925 (0.003 $\mu \mathrm{m}$ paclitaxel-NSC23925); cells selected with $0.006 \mu \mathrm{m}$ paclitaxel in the presence of $1 \mu \mathrm{m}$ NSC23925 (0.006 $\mu \mathrm{m}$ paclitaxel-NSC23925); and cells selected with paclitaxel alone at different concentrations: $0.003 \mu \mathrm{m}(0.003 \mu \mathrm{m}$ paclitaxel), $0.006 \mu \mathrm{m}(0.006 \mu \mathrm{m}$ paclitaxel), $0.01 \mu \mathrm{m}(0.01 \mu \mathrm{m}$ paclitaxel), $0.03 \mu \mathrm{m}(0.03 \mu \mathrm{m}$ paclitaxel), $0.06 \mu \mathrm{M}$ $(0.06 \mu \mathrm{m}$ paclitaxel), $0.1 \mu \mathrm{m}(0.1 \mu \mathrm{m}$ paclitaxel) and $0.2 \mu \mathrm{m}$ paclitaxel $(0.2 \mu \mathrm{m}$ paclitaxel); U-2OSR2. (B) The IC 50 of paclitaxel in Saos parental cell and selected cell sublines. Data are presented as mean \pm s.d. 
A

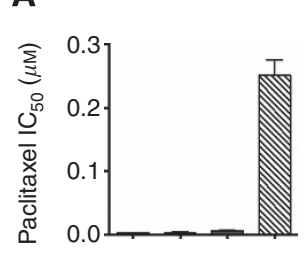

$\mathbf{E}$

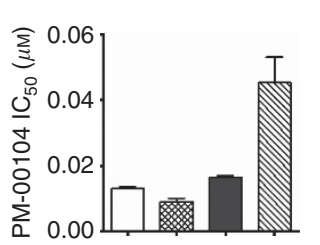

B

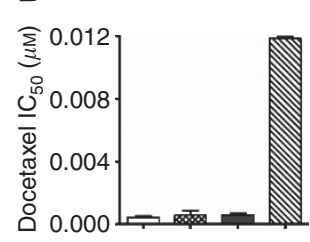

$\mathbf{F}$

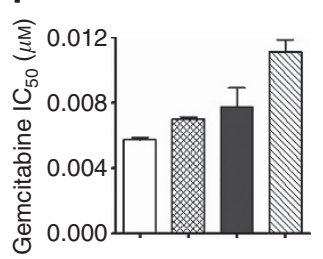

C

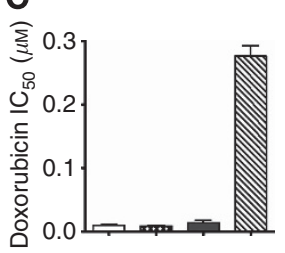

G

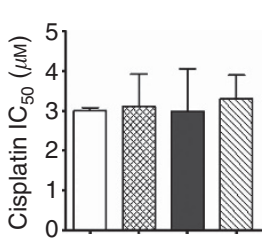

$\square$ U-20S parental

खU-20S/NSC23925

$\square$ U-20S/paclitaxel 0.006 -NSC23925

$\square$ U-20S/paclitaxel 0.2
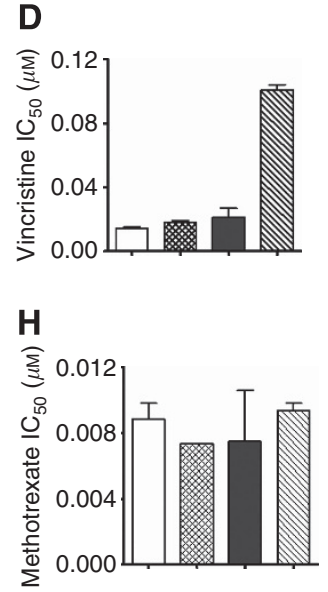

Figure 3. The NSC23925 inhibited the introduction of cross-resistance to chemotherapeutic agents. The U-2OS/paclitaxel $0.006-\mathrm{NSC} 23925$ cells showed sensitivity to paclitaxel (A), docetaxel (B), doxorubicin (C), vincrisine (D), PM-00104 (E) and gemcitabine (F), whereas U-2OS/paclitaxel 0.2 cells displayed resistance to these drugs. The cytotoxicity of cisplatin (G) and methotrexate (H) did not change in both U-2OS/paclitaxel $0.006-\mathrm{NSC} 23925$ and U-2OS/paclitaxel 0.2 cells. No changes in cytotoxicity of chemotherapeutic agents were seen in U-2OS/ NSC23925 cells. Data are presented as mean \pm s.d.

It is well known that Pgp is not the sole mechanism of MDR. Therefore, the expression level of other important drug transporter proteins including BCRP and MRP1 was also assessed in different cell sublines. All of the U-2OS and Saos cell sublines exhibited low expression of BCRP, and protein expression of MRP1 was undetectable (Figure $4 \mathrm{~A}$ and $\mathrm{B}$ ). No difference of MRP1 and BCRP levels among the cell sublines revealed that MRP1 and BCRP were not associated with the introduction of drug resistance selected by paclitaxel treatment. Thus, these observations suggested that NSC23925 specifically suppressed the expression of Pgp to prevent the emergence of MDR during chemotherapeutic drug treatment.

NSC23925 prevents decreased drug intracellular accumulation by preventing the overexpression of Pgp during paclitaxel treatment. The intracellular accumulation and efflux levels of Pgp substrates were examined to confirm the functional activity of the Pgp in different U-2OS cell sublines. U-2OS/ paclitaxel $_{0.006}-\mathrm{NSC} 23925$ cells showed a considerable higher intracellular accumulation of Calcein AM and R123 as compared with U-2OS/paclitaxel ${ }_{0.2}$ cells. Notably, U-2OS/ paclitaxel $0_{0.006}-\mathrm{NSC} 23925$ cells showed similar Pgp substrate intracellular accumulation levels when compared with parental cells (Figure 5A and B). Furthermore, a statistical lower relative efflux level of R123 was detected in U-2OS/paclitaxel $\mathrm{L}_{0.006}$ NSC23925 cells than in U-2OS/paclitaxel ${ }_{0.2}$ cells (Figure 5B). The accumulation and efflux activity of Pgp substrates were consistent with the degree of Pgp expression. In addition, cells with longer exposure to NSC23925 alone had no obvious effect on Pgp activity. These results strongly indicated that the increased expression of Pgp resulted in the decreased intracellular accumulation and increased efflux of Pgp substrates.

\section{DISCUSSION}

NSC23925 is a novel methoxyphenyl piperidinyl compound (http://pubchem.ncbi.nlm.nih.gov/) with a molecular weight of $348 \mathrm{~g} \mathrm{~mol}^{-1}$. The information about the pharmacological action of
NSC23925 is lacking. Reflective of our findings that NSC23925 can reverse MDR by stimulating Pgp ATPase activity and inhibiting the function of Pgp in a variety of MDR cancer cells (Duan et al, 2009a, 2012), the present study further demonstrated that NSC23925 has the ability to prevent the development of MDR in human osteosarcoma U-2OS and Saos cells. The U-2OS and Saos cells selected with paclitaxel alone developed a MDR phenotype with resistance to paclitaxel and cross-resistance to Pgp substrates doxorubicin, docetaxel, vincristine and PM-00104. However, cells selected with paclitaxel-NSC23925 simultaneously remained sensitive to chemotherapeutic agents. Interestingly, cells selected with paclitaxel alone showed significant higher Pgp expression than cells selected with paclitaxel-NSC23925 combination and parental cells. Specifically, cells selected with paclitaxel-NSC23925 combination displayed similar Pgp expression level to their parental cells. The extent of MDR in selected cells correlated with the Pgp expression level. Furthermore, cells selected with paclitaxel or paclitaxel-NSC23925 combination remained sensitive to nonPgp substrates cisplatin and methotrexate, and no changes in BCRP and MRP1 expression were seen in different cell sublines. Our findings indicate that NSC23925 can prevent the emergence of MDR in osteosarcoma by specifically preventing the expression of Pgp during chemotherapeutic drug treatment.

We observed that exposure of cells to paclitaxel led to overexpression of Pgp, and increased Pgp expression level was responsible for the emergence of $\mathrm{MDR}$, consistent with previous research results suggesting that overexpression of Pgp plays a major role in the molecular mechanisms of MDR (Suto et al, 1998; Gottesman et al, 2002; Ozben, 2006; Sharma et al, 2008). The Pgp rapidly pumps out functionally and structurally distinct chemotherapeutic drugs from cells, acting as an energy-dependent membrane transporter. Therefore, overexpression of Pgp results in reduced intracellular accumulation of drugs and prevents the drugs from exerting their cytotoxic effects (Szakacs et al, 2006). Our data showed that paclitaxel-selected drug-resistant cells displayed decreased drug intracellular accumulation and enhanced drug efflux. In comparison, cancer cells selected with paclitaxelNSC23925 combination showed similar drug uptake/efflux level as parental sensitive cells. NSC23925 prevents the increased 

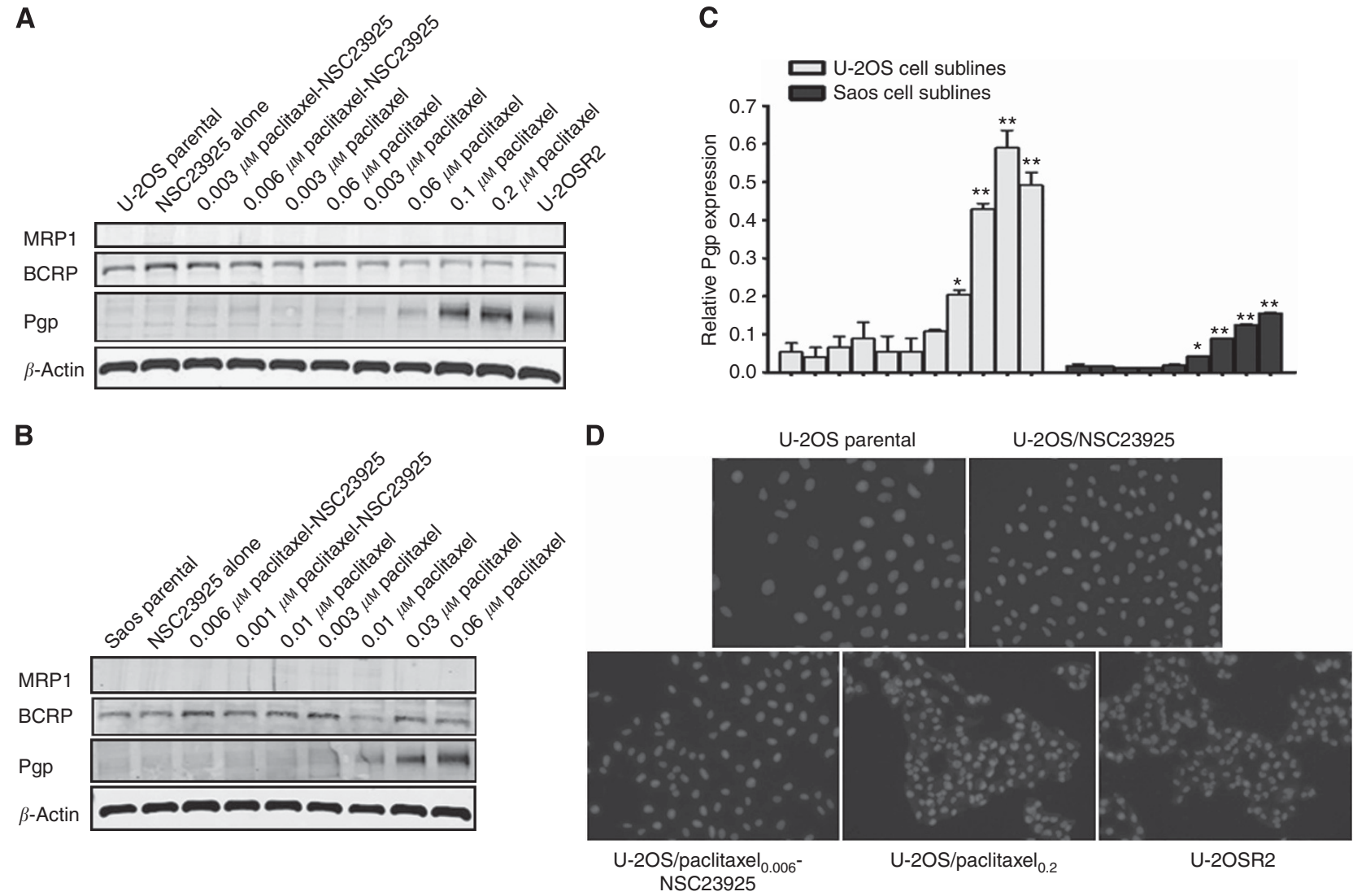

Figure 4. The NSC23925 specifically prevented Pgp overexpression during paclitaxel treatment. (A and B) Expression level of Pgp, BCRP and MRP1 in different U-2OS and Saos cell sublines detected by western blot, respectively. Western blot analysis demonstrated that U-2OS/paclitaxel and Saos/paclitaxel cells eventually expressed significantly higher Pgp. However, no significant change in Pgp expression level was observed in U-2OS/paclitaxel-NSC23925 and Saos/paclitaxel-NSC23925 cells compared with parental cells. Increases in the Pgp level detected in the different cell sublines showed a strong association with the increase in the concentration of paclitaxel tolerated by cells. No significant difference of MRP1 and BCRP levels were observed among the different cell sublines. (C) Relative Pgp expression of western blot from (A and B) were analysed by densitometry. The labels correspond to those given in (A and B). Data are presented as means \pm s.d. and analysed using Student's t-test (two tailed, unequal variance). Statistical comparisons between selected and parental cells are presented: ${ }^{\star} P<0.05$, ${ }^{\star \star} P<0.005,{ }^{\star \star \star} P<0.001$. (D) Expression level of Pgp in U-2OS cell sublines analysed by immunofluorescence. The U-2OS/paclitaxel 0.2 cells displayed significantly higher Pgp staining than U-2OS/paclitaxel $0.006-\mathrm{NSC23925}$ cells.

expression of Pgp and therefore prevents increased efflux and/or decreased influx of drugs during chemotherapy treatment. These findings provide an indication of the mechanism by which NSC23925 prevents the emergence of MDR in osteosarcoma (Figure 6). NSC23925 specifically prevented the overexpression of Pgp during the chemotherapeutic drug treatment that subsequently allowed for the retention of intercellular drug accumulation and decreased drug efflux. Consequently, NSC23925 enabled tumour cells to remain sensitive to chemotherapeutic drug and prevented the emergence of MDR during chemotherapy treatment.

The inclusion of drugs or agents that can prevent the development of MDR may enable patients who initially responded to therapy to continue responding without the development of MDR, and therefore provide significant clinical benefits. Preventing the overexpression of Pgp has been identified as an efficient approach to inhibit the development of MDR during chemotherapeutic drug treatment (Cocker et al, 2001; Yen and Lamph, 2006; Zatelli et al, 2007). There are several drugs that act on the same mechanism of preventing the development of MDR with NSC23925 by suppressing the overexpression of Pgp, such as PSC833, VX710 and P85 (Cocker et al, 2001; Batrakova et al, 2006; Batrakova and Kabanov, 2008; Sharma et al, 2008). Unfortunately, PSC833, a nonimmunosuppressive cyclosporin D derivative, was shown to have pharmacokinetic interactions with paclitaxel and inhibited non-MDR-related transporters (Kang et al, 2001; Bates et al, 2004). Although VX-710 has no pharmacokinetic interactions with paclitaxel and doxorubicin, myelosuppression and nonhaematologic toxicity have restricted this clinical application (Seiden et al, 2002). The addition of VX-710 to vincristine and doxorubicin therapy did not statistically enhance antitumour activity or survival in recurrent small cell lung cancer (Gandhi et al, 2007). In the present study, no significant changes on cell chemosensitivity, Pgp expression or Pgp activity were observed in osteosarcoma cells with longer exposure to NSC23925 alone in vitro. Moreover, both NSC23925 alone and paclitaxel-NSC23925 combination do not alter Pgp expression levels and activity in osteosarcoma cells. On the basis of animal weight and mortality, no significant toxicity was observed and the mice appeared to have tolerated it well when NSC23925 was administered alone in our previous study (Duan et al, 2012). Taken together, these observations may suggest that NSC23925 has no pharmacokinetic interactions with paclitaxel, and cannot increase drug toxicity in vitro. However, whether NSC23925 has pharmacokinetic interactions with anticancer drugs and other side effects in vivo deserves further investigation. P85 has also been demonstrated to prevent the introduction of MDR1 phenotype by preventing the overexpression of Pgp in leukemia cell line P388 as well as human breast carcinoma cell line MCF7 (Batrakova et al, 2006; Sharma et al, 2008). The $\mathrm{IC}_{50}$ of cells 
A

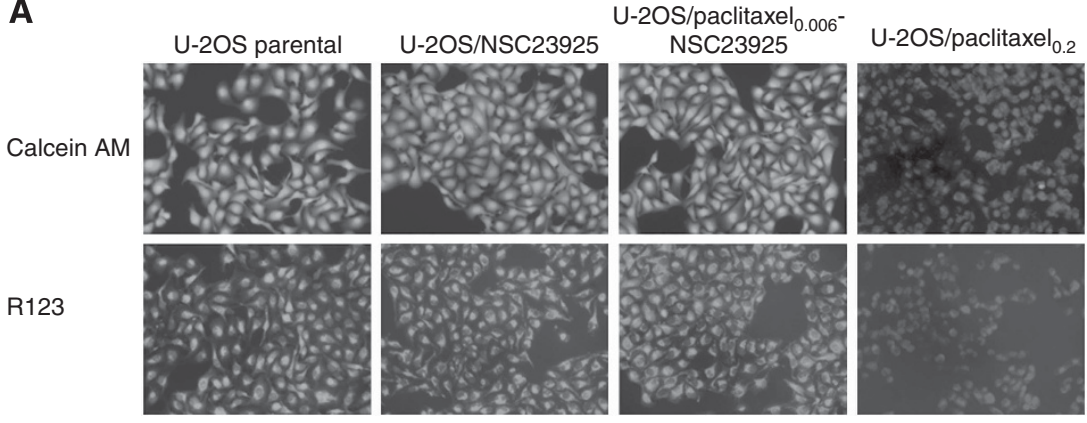

B

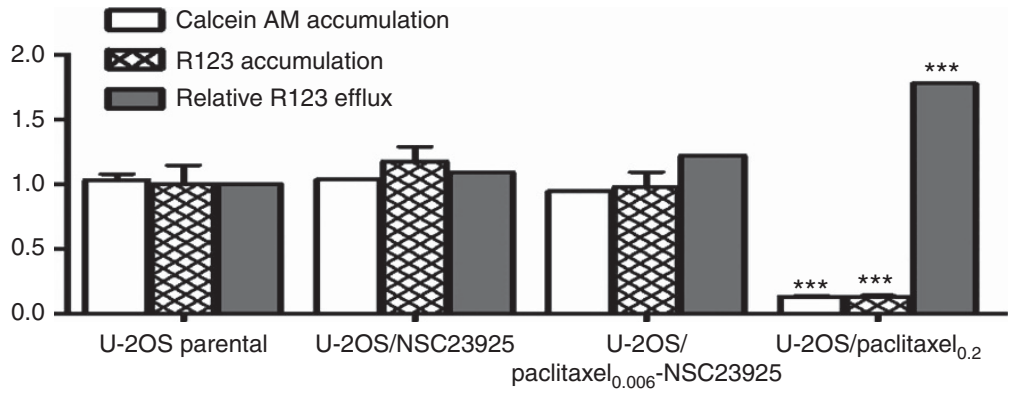

Figure 5. Pgp activity in different cell sublines. (A) Drug intracellular accumulation images of U-2OS cell sublines incubated with Calcein AM and

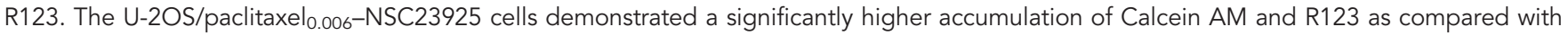
U-2OS/paclitaxel 0.2 cells. (B) Calcein AM accumulation and R123 accumulation and efflux level in U-2OS cell sublines analysed by Microplate Spectrofluorometer. The U-2OS/paclitaxel $\mathrm{0}_{0.006}$-NSC23925 cells showed a statistically higher accumulation of Calcein AM, R123 and lower relative efflux level of R123 than U-2OS/paclitaxel 0.2 cells. Cells cultured with NSC23925 alone had no obvious effect on Pgp activity. Data are presented as mean \pm s.d. and analysed using Student's t-test (two tailed, unequal variance). Statistical comparisons between selected and parental cells are presented: ${ }^{\star} P<0.05,{ }^{*} P<0.005,{ }^{* \star *} P<0.001$.

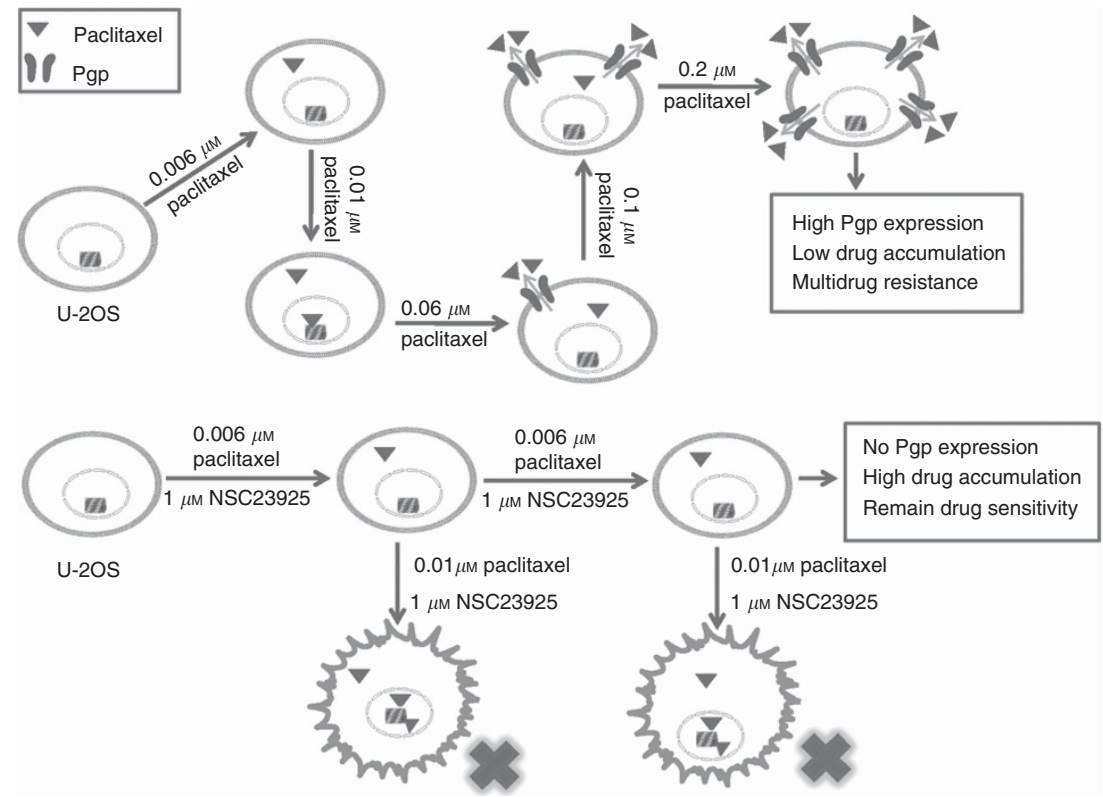

Figure 6. The mechanism by which NSC23925 acts to prevent the emergence of MDR in osteosarcoma. The U-2OS cells selected with paclitaxel alone developed a MDR phenotype with resistance to Pgp substrates, as well as decreased drug intracellular accumulation and enhanced drug efflux. However, NSC23925 specifically prevented overexpression of Pgp during chemotherapeutic drug treatment that subsequently allowed for the retention of intercellular drug accumulation and decreased drug efflux. Consequently, NSC23925 enabled tumour cells to remain sensitive to chemotherapeutic drugs and prevented the emergence of MDR during chemotherapy treatment.

selected with doxorubicin in the presence of P85 increased 6.13 -fold in vitro and 5.58-fold in vivo as compared with parental P388 cells. In contrast, $\mathrm{IC}_{50}$ of cells selected with paclitaxel in the presence of NSC23925 increased by 0.8 - or 0.6-fold compared with $\mathrm{IC}_{50}$ of parental cells. Hence, NSC23925 may have a greater effect on preventing the development of MDR than P85.
In summary, our findings indicate that NSC23925 can prevent the development of MDR in osteosarcoma by specifically preventing the overexpression of Pgp during chemotherapeutic drug treatment. These results suggest that NSC23925 will be useful in extending the long-term efficacy of chemotherapy by preventing the development of Pgp-mediated MDR in the clinical setting. 


\section{ACKNOWLEDGEMENTS}

This work was supported in part by grants from the Gattegno and Wechsler funds. Support has also been provided by the Kenneth Stanton Fund. Dr Duan is supported, in part, through a grant from the Sarcoma Foundation of America (SFA) and a grant from the National Cancer Institute (NCI)/National Institutes of Health (NIH), UOI, CA 151452. Dr Yang is supported by scholarship from the China Scholarship Council.

\section{CONFLICT OF INTEREST}

The authors declare no conflict of interest.

\section{REFERENCES}

Agarwal R, Kaye SB (2003) Ovarian cancer: strategies for overcoming resistance to chemotherapy. Nat Rev Cancer 3(7): 502-516.

Baer MR, George SL, Dodge RK, O’Loughlin KL, Minderman H, Caligiuri MA, Anastasi J, Powell BL, Kolitz JE, Schiffer CA, Bloomfield CD, Larson RA (2002) Phase 3 study of the multidrug resistance modulator PSC-833 in previously untreated patients 60 years of age and older with acute myeloid leukemia: Cancer and Leukemia Group B Study 9720. Blood 100(4): 1224-1232.

Bates SE, Bakke S, Kang M, Robey RW, Zhai S, Thambi P, Chen CC, Patil S, Smith T, Steinberg SM, Merino M, Goldspiel B, Meadows B, Stein WD, Choyke P, Balis F, Figg WD, Fojo T (2004) A phase I/II study of infusional vinblastine with the P-glycoprotein antagonist valspodar (PSC 833) in renal cell carcinoma. Clin Cancer Res 10(14): 4724-4733.

Batrakova EV, Kabanov AV (2008) Pluronic block copolymers: evolution of drug delivery concept from inert nanocarriers to biological response modifiers. J Control Release 130(2): 98-106.

Batrakova EV, Kelly DL, Li S, Li Y, Yang Z, Xiao L, Alakhova DY, Sherman S, Alakhov VY, Kabanov AV (2006) Alteration of genomic responses to doxorubicin and prevention of MDR in breast cancer cells by a polymer excipient: pluronic P85. Mol Pharm 3(2): 113-123.

Bodey B, Taylor CR, Siegel SE, Kaiser HE (1995) Immunocytochemical observation of multidrug resistance (MDR) p170 glycoprotein expression in human osteosarcoma cells. The clinical significance of MDR protein overexpression. Anticancer Res 15(6B): 2461-2468.

Chano T, Mori K, Scotlandi K, Benini S, Lapucci C, Manara MC, Serra M, Picci P, Okabe H, Baldini N (2004) Differentially expressed genes in multidrug resistant variants of U-2 OS human osteosarcoma cells. Oncol Rep 11(6): 1257-1263.

Chou AJ, Geller DS, Gorlick R (2008) Therapy for osteosarcoma: where do we go from here? Paediatr Drugs 10(5): 315-327.

Chou AJ, Gorlick R (2006) Chemotherapy resistance in osteosarcoma: current challenges and future directions. Expert Rev Anticancer Ther 6(7): 1075-1085.

Cocker HA, Tiffin N, Pritchard-Jones K, Pinkerton CR, Kelland LR (2001) In vitro prevention of the emergence of multidrug resistance in a pediatric rhabdomyosarcoma cell line. Clin Cancer Res 7(10): 3193-3198.

Decaudin D, Castedo M, Nemati F, Beurdeley-Thomas A, De Pinieux G, Caron A, Pouillart P, Wijdenes J, Rouillard D, Kroemer G, Poupon MF (2002) Peripheral benzodiazepine receptor ligands reverse apoptosis resistance of cancer cells in vitro and in vivo. Cancer Res 62(5): 1388-1393.

Dieudonne FX, Marion A, Hay E, Marie PJ, Modrowski D (2010) High Wnt signaling represses the proapoptotic proteoglycan syndecan-2 in osteosarcoma cells. Cancer Res 70(13): 5399-5408.

Duan Z, Choy E, Hornicek FJ (2009a) NSC23925, identified in a highthroughput cell-based screen, reverses multidrug resistance. PLoS One 4(10): e7415.

Duan Z, Choy E, Jimeno JM, Cuevas Cdel M, Mankin HJ, Hornicek FJ (2009b) Diverse cross-resistance phenotype to ET-743 and PM00104 in multi-drug resistant cell lines. Cancer Chemother Pharmacol 63(6): 1121-1129.

Duan Z, Li X, Huang H, Yuan W, Zheng SL, Liu X, Zhang Z, Choy E, Harmon D, Mankin H, Hornicek F (2012) Synthesis and evaluation of (2-(4-methoxyphenyl)-4-quinolinyl)(2-piperidinyl)methanol (NSC23925) isomers to reverse multidrug resistance in cancer. J Med Chem 55(7): 3113-3121.

Gandhi L, Harding MW, Neubauer M, Langer CJ, Moore M, Ross HJ, Johnson BE, Lynch TJ (2007) A phase II study of the safety and efficacy of the multidrug resistance inhibitor VX-710 combined with doxorubicin and vincristine in patients with recurrent small cell lung cancer. Cancer 109(5): 924-932.

Gillet JP, Gottesman MM (2010) Mechanisms of multidrug resistance in cancer. Methods Mol Biol 596: 47-76.

Gottesman MM, Fojo T, Bates SE (2002) Multidrug resistance in cancer: role of ATP-dependent transporters. Nat Rev Cancer 2(1): 48-58.

Gupta SC, Patchva S, Koh W, Aggarwal BB (2012) Discovery of curcumin, a component of golden spice, and its miraculous biological activities. Clin Exp Pharmacol Physiol 39(3): 283-299.

Higgins CF (2007) Multiple molecular mechanisms for multidrug resistance transporters. Nature 446(7137): 749-757.

Kang MH, Figg WD, Ando Y, Blagosklonny MV, Liewehr D, Fojo T, Bates SE (2001) The P-glycoprotein antagonist PSC 833 increases the plasma concentrations of 6alpha-hydroxypaclitaxel, a major metabolite of paclitaxel. Clin Cancer Res 7(6): 1610-1617.

Kelly RJ, Draper D, Chen CC, Robey RW, Figg WD, Piekarz RL, Chen X, Gardner ER, Balis FM, Venkatesan AM, Steinberg SM, Fojo T, Bates SE (2011) A pharmacodynamic study of docetaxel in combination with the P-glycoprotein antagonist tariquidar (XR9576) in patients with lung, ovarian, and cervical cancer. Clin Cancer Res 17(3): $569-580$.

Kobayashi E, Iyer AK, Hornicek FJ, Amiji MM, Duan Z (2012) Lipidfunctionalized dextran nanosystems to overcome multidrug resistance in cancer: a pilot study. Clin Orthop Relat Res 471(3): 915-925.

Kolitz JE, George SL, Marcucci G, Vij R, Powell BL, Allen SL, DeAngelo DJ, Shea TC, Stock W, Baer MR, Hars V, Maharry K, Hoke E, Vardiman JW, Bloomfield CD, Larson RA (2010) P-glycoprotein inhibition using valspodar (PSC-833) does not improve outcomes for patients younger than age 60 years with newly diagnosed acute myeloid leukemia: Cancer and Leukemia Group B study 19808. Blood 116(9): 1413-1421.

Lhomme C, Joly F, Walker JL, Lissoni AA, Nicoletto MO, Manikhas GM, Baekelandt MM, Gordon AN, Fracasso PM, Mietlowski WL, Jones GJ, Dugan MH (2008) Phase III study of valspodar (PSC 833) combined with paclitaxel and carboplatin compared with paclitaxel and carboplatin alone in patients with stage IV or suboptimally debulked stage III epithelial ovarian cancer or primary peritoneal cancer. J Clin Oncol 26(16): 2674-2682.

Lin YG, Kunnumakkara AB, Nair A, Merritt WM, Han LY, Armaiz-Pena GN, Kamat AA, Spannuth WA, Gershenson DM, Lutgendorf SK, Aggarwal BB, Sood AK (2007) Curcumin inhibits tumor growth and angiogenesis in ovarian carcinoma by targeting the nuclear factor-kappaB pathway. Clin Cancer Res 13(11): 3423-3430.

Marina N, Gebhardt M, Teot L, Gorlick R (2004) Biology and therapeutic advances for pediatric osteosarcoma. Oncologist 9(4): 422-441.

Minderman H, O'Loughlin KL, Pendyala L, Baer MR (2004) VX-710 (biricodar) increases drug retention and enhances chemosensitivity in resistant cells overexpressing P-glycoprotein, multidrug resistance protein, and breast cancer resistance protein. Clin Cancer Res 10(5): 1826-1834.

O’Brien MM, Lacayo NJ, Lum BL, Kshirsagar S, Buck S, Ravindranath Y, Bernstein M, Weinstein H, Chang MN, Arceci RJ, Sikic BI, Dahl GV (2010) Phase I study of valspodar (PSC-833) with mitoxantrone and etoposide in refractory and relapsed pediatric acute leukemia: a report from the Children's Oncology Group. Pediatr Blood Cancer 54(5): 694-702.

Okada T, Tanaka K, Nakatani F, Sakimura R, Matsunobu T, Li X, Hanada M, Nakamura T, Oda Y, Tsuneyoshi M, Iwamoto Y (2006) Involvement of P-glycoprotein and MRP1 in resistance to cyclic tetrapeptide subfamily of histone deacetylase inhibitors in the drug-resistant osteosarcoma and Ewing's sarcoma cells. Int J Cancer 118(1): 90-97.

Ozben T (2006) Mechanisms and strategies to overcome multiple drug resistance in cancer. FEBS Lett 580(12): 2903-2909.

Ryu K, Susa M, Choy E, Yang C, Hornicek FJ, Mankin HJ, Duan Z (2010) Oleanane triterpenoid CDDO-Me induces apoptosis in multidrug resistant osteosarcoma cells through inhibition of Stat3 pathway. BMC Cancer 10: 187.

Sakamoto A, Iwamoto Y (2008) Current status and perspectives regarding the treatment of osteo-sarcoma: chemotherapy. Rev Recent Clin Trials 3(3): $228-231$. 
Seiden MV, Swenerton KD, Matulonis U, Campos S, Rose P, Batist G, Ette E, Garg V, Fuller A, Harding MW, Charpentier D (2002) A phase II study of the MDR inhibitor biricodar (INCEL, VX-710) and paclitaxel in women with advanced ovarian cancer refractory to paclitaxel therapy. Gynecol Oncol 86(3): 302-310.

Sharma AK, Zhang L, Li S, Kelly DL, Alakhov VY, Batrakova EV, Kabanov AV (2008) Prevention of MDR development in leukemia cells by micelleforming polymeric surfactant. J Control Release 131(3): 220-227.

Shukla S, Ohnuma S, Ambudkar SV (2011) Improving cancer chemotherapy with modulators of ABC drug transporters. Curr Drug Targets 12(5): 621-630.

Susa M, Iyer AK, Ryu K, Choy E, Hornicek FJ, Mankin H, Milane L, Amiji MM, Duan Z (2010) Inhibition of ABCB1 (MDR1) expression by an siRNA nanoparticulate delivery system to overcome drug resistance in osteosarcoma. PLoS One 5(5): e10764.

Suto R, Abe Y, Nakamura M, Ohnishi Y, Yoshimura M, Lee YH, Imanishi T, Yamazaki H, Kijima H, Tokunaga T, Oshika Y, Hiraoka N, Tamaoki N, Fukuda H, Ueyama Y (1998) Multidrug resistance mediated by overexpression of P-glycoprotein in human osteosarcoma in vivo. Int J Oncol 12(2): 287-291.

Szakacs G, Paterson JK, Ludwig JA, Booth-Genthe C, Gottesman MM (2006) Targeting multidrug resistance in cancer. Nat Rev Drug Discov 5(3): 219-234.
Tooker P, Yen WC, Ng SC, Negro-Vilar A, Hermann TW (2007) Bexarotene (LGD1069, Targretin), a selective retinoid $\mathrm{X}$ receptor agonist, prevents and reverses gemcitabine resistance in NSCLC cells by modulating gene amplification. Cancer Res 67(9): 4425-4433.

Yen WC, Corpuz MR, Prudente RY, Cooke TA, Bissonnette RP, Negro-Vilar A, Lamph WW (2004) A selective retinoid X receptor agonist bexarotene (Targretin) prevents and overcomes acquired paclitaxel (Taxol) resistance in human non-small cell lung cancer. Clin Cancer Res 10(24): 8656-8664.

Yen WC, Lamph WW $(2006)$ A selective retinoid X receptor agonist bexarotene (LGD1069, Targretin) prevents and overcomes multidrug resistance in advanced prostate cancer. Prostate 66(3): 305-316.

Zatelli MC, Luchin A, Tagliati F, Leoni S, Piccin D, Bondanelli M, Rossi R, degli Uberti EC (2007) Cyclooxygenase-2 inhibitors prevent the development of chemoresistance phenotype in a breast cancer cell line by inhibiting glycoprotein p-170 expression. Endocr Relat Cancer 14(4): 1029-1038.

This work is published under the standard license to publish agreement. After 12 months the work will become freely available and the license terms will switch to a Creative Commons AttributionNonCommercial-Share Alike 3.0 Unported License.

Supplementary Information accompanies this paper on British Journal of Cancer website (http://www.nature.com/bjc) 